invoked in any theory of colour vision. For example, the sensation of "Brown" cannot be obtained directly from stimulation of the retina by any pure spectral rays or any admixture of such. It can be produced by mixing red or orange pigment with black pigment; but it can also be produced by receiving the pure spectral stimulus on a patch of retina in which the black after-image of a white light has been induced.

Further, the plotting of the sensation curves on' a plane surface results in the familiar colour triangle. In any such triangle the red, and to a more doubtful extent the violet, are fully saturated, but the green angle of the triangle is very unsaturated.' This indicates that there is a hypothetical green sensation far more saturated than spectral green. Anyone who has stimulated his * retina with spectral green after previously stimulating it with the complementary purple will obtain a sensation of green which is much more saturated than any green which he has seen before.

The author, from other experinents-on individual variation in the position and range of pure yellow in the spectrum, and on the thresholds for colour sensation of monochromatic light within the indigo region of the spectrum-concludes that the fundamental colours are red, green, and blue. He further holds that "every impulse from the retinal receptors to a colour sensation is necessarily combined with a certain degree of central inhibition of the complementary colour in the same area, the degree of this inhibition being bounded by a certain law." The theory is illustrated by the help of a compound balance model.

\title{
CORRESPONDENCE
}

\section{Re TREATMENT OF STREPTOTHRICOSIS CONJUNCTIVAE WITH GUTTAE SODIUM SULPHACETAMIDE 30 PER GENT.}

\section{To the Editors of THE BRITISH JOURNAL OF OPHTHALMOLOGy.}

DEAR SIRS,-In May this year I saw a typical case of streptothricosis of the conjunctiva in a 14 months old male baby. The conjunctiva of the right lower lid was covered with many yellowwhitish nodules, which were so numerous that they gave the appearance of a pseudo membrane, which was adherent to the follicles of the conjunctiva. There was no discharge or watering of the eye, and the eyeball showed scarcely any conjunctival injection. 
No yellow nodules were found on the upper palpebral conjunctiva, but a few follicles.

The left eye showed merely the picture of a follicular conjunctivitis, with a few yellowish nodules adherent to the lower palpebral conjunctiva. There was no swelling of the pre-auricular glands.'

It was impossible to remove the nodules with gauze or cottonwool. The baby was otherwise in perfect health, and there was no history of any previous illness. A smear was taken, but did not show anything except for a few cocci. It was àrranged to do a biopsy of the conjunctiva, and guttae sodium sulphacetamilde, 30 per cent., were ordered in the meantime.

- To my great surprise, the condition had completely cleared up when the child was seen a fortnight later. This is the more remarkable as the lesion is situated beneath the epithelium, and the usual treatment recommended is excision of the yellow nodules.

- A short time later I saw an old lady with streptothrix concretions in the lower canaliculus. I It had produced a conjunctivitis and a nasty corneal ulceration of the eye.

I removed a large, foul-smelling mass, which had the shape of a sausage, and measured twenty by three millimetres, from the canaliculus and lacrymal sac. Histological examination showed streptothrix, with secondary infection. Guttae sodium sulphacetamide, 30 per cent., cleared up the infection within three weeks.

$$
\text { I am, Sirs, }
$$

\section{Your obedient servant,}

J. A. Magnus.

25, High Petergate, York.

September, 23, 1943.

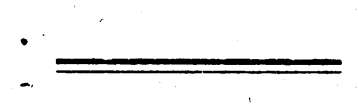

\section{NOTES}

Royal Society of Medicine, Section of Ophthalmology

- November 12, 1943; February 11, March 31 and June 9, 1944; in each case at 5 p.m. Cases half-an-hour earlier. The March meeting it is hoped will be a joint meeting with the Ophthalmological Society of the United Kingdom. 